\title{
Estudo do potencial hidrogeniônico e das condições físicas dos clubes de Pombal - PB
}

\section{Study of the hidrgeniônico potential and physical conditions of the clubs of Pombal -} $\boldsymbol{P B}$

\author{
Geanny Alves de Sousa Lima ${ }^{1}$, Andréa Maria Brandão Mendes de Oliveira ${ }^{2}$, Luiz Fernando de Oliveira Coelho ${ }^{3}$, Carlos \\ Eduardo Pereira de Morais ${ }^{4}$
}

Resumo: As piscinas são um conjunto de estruturas artificiais que levam ao ser humano um contato direto com a água através de atividades aquáticas, como a natação. A qualidade da água das piscinas, assim como a estrutura física onde ela se comporta, são fatores de fundamental importância e por isso devem ser estudados, na busca de se obter uma melhor funcionalidade deste ambiente, bem como garantir a saúde dos usuários. A utilização deste recurso tem sido realizada de forma livre sem uma fiscalização adequada, trazendo consequências, como a proliferação de bactérias e/ou transmissão de outras doenças. Por estes motivos torna-se relevante o presente estudo, que teve como objetivo principal a análise de água e estrutura física das piscinas dos clubes públicos de Pombal-PB localizada na mesorregião do sertão paraibano.

Palavras-Chave: piscinas, Análise físico-química, Saúde.

\begin{abstract}
The pools are a set of artificial structures that lead to human being a direct contact with the water through water activities such as swimming. The water quality of swimming pools, as well as the physical structure where she behaves, are factors of paramount importance and therefore should be studied, in search of a better functionality of this environment as well as ensure the health of users. The use of this resource has been carried out freely without an adequate oversight, bringing consequences, such as the proliferation of bacteria and/or transmission of other diseases. For these reasons it becomes relevant to the present study, which had as main objective the analysis of water and physical structure of the pools of public clubs of Pombal-PB in the Northeast region of Brazil.
\end{abstract}

Keywords: pools, physical-chemical Analysis, health.

\footnotetext{
*Autor para correspondência

Recebido para publicação em 01/08/2015; aprovado em 29/09/2015

${ }^{1}$ Aluna do Curso de Engenharia Ambiental - Universidade Federal de Campina Grande - UFCG/UACTA, Campus Pombal PB - Rua Jairo Viera Feitosa, ${ }^{\circ}$ 1770, Bairro dos Pereiros, CEP: 58840-000.

${ }^{2}$ Engenheira Química, Professora Doutora - Universidade Federal de Campina Grande - UFCG/UACTA, Campus Pombal PB - Rua Jairo Viera Feitosa, ${ }^{\circ}$ 1770, Bairro dos Pereiros, CEP: 58840-000.Ee-mail: andrea.maria@ufcg.edu.br

${ }^{3}$ Técnico em Química -Universidade Federal de Campina Grande - UFCG/UACTA, Campus Pombal PB - Rua Jairo Viera Feitosa, ${ }^{\circ}$ 1770, Bairro dos Pereiros, CEP: 58840-000. E-mail: luisfoc@ccta.ufcg.edu.br

${ }^{4}$ Aluno do Curso de Engenharia Ambiental - Universidade Federal de Campina Grande - UFCG/UACTA, Campus Pombal PB - Rua Jairo Viera Feitosa, ${ }^{\circ}$ 1770, Bairro dos Pereiros, CEP: 58840-000. E-mail: carlospereira.sjp@ gmail.com
} 


\section{INTRODUÇÃO}

As piscinas são definidas pela Norma Brasileira Regulamentadora, NBR 9816/1987 como conjunto de instalações destinadas às atividades aquáticas, compreendendo o tanque e demais componentes relacionados com o seu uso e funcionamento.

Os clubes aquáticos possuem um grande valor social, pois apresentam em seus conjuntos de instalações piscinas que são destinadas ao lazer e a prática esportiva, e dessa forma estão relacionados com a saúde física e mental do ser humano. Contudo o prazer de se frequentar uma piscina não pode esconder o fato de existirem perigos de riscos associados à estrutura, aos subprodutos da desinfecção da água e aos riscos microbiológicos.

A NBR 9818:1987 fixa as condições exigíveis quanto à forma e aos critérios pelos quais devem ser projetados e construídos os tanques de piscinas, para atender às exigências técnicas mínimas de higiene, segurança e conforto dos usuários. Deste modo define-se o tratamento e comportamento aceitável na piscina, água e estrutura local, para uso humano sem que haja malefícios a saúde e segurança dos usuários. Porém a norma não sujeita ao proprietário efetuar um tratamento da água rigorosamente preciso e sim um tratamento físico e químico que aparente uma água limpa e cristalina, sem importar os fatores essenciais que precisam ser atendidos, como a analise bacteriológica. Deixando assim os usuários expostos a diferentes tipos bactérias que podem vir a transmitir doenças aos mesmos, e por ventura venha a denegrir a imagem do local.

A NBR 10818/1989 diz que a limpidez da água deve ser tal que permita a visibilidade da parte mais profunda do tanque. A superfície da água deve está livre de materiais flutuantes estranhas a piscinas e o fundo do tanque livre de detritos.

Para se adequarem a esta normativa os clubes aquáticos realizam manutenção, porém de forma livre sem uma fiscalização adequada. O problema reside no fato de todos os produtos químicos poderem ser contaminantes e, por isso, deverão ser utilizados apenas quando necessário e na medida certa de modo a não haver uma utilização abusiva.

Os desinfetantes utilizados para o tratamento da água são os principais produtos químicos que formam subprodutos que interferem com a qualidade da água e do ar nas piscinas (BELEZA et al., 2007). Todos os desinfetantes à base de cloro geram ácido hipocloroso $(\mathrm{HClO})$ ao reagir com a água, sendo esta a forma ativa do cloro com maior capacidade de desinfecção, destruindo as paredes celulares dos microrganismos (BELEZA et al., 2007). Apesar do HClO ter a capacidade de desativar a maior parte dos microrganismos presentes nas piscinas, este também é um composto quimicamente reativo pois reagindo com a matéria orgânica, por exemplo, a introduzida pelos banhistas através da urina, suor, saliva, etc., forma subprodutos de desinfecção (JUDD E JEFFREY, 1994).

Os subprodutos de desinfecção vão variar conforme o tipo de desinfetante usado. No caso da utilização de derivados do cloro, os principais subprodutos são: trihalometanos, ácidos haloacéticos, haloacetonitrilos, haloacetonas, tricloroacetaldeído, tricloronitrometano, cloreto de cianogênio, clorato e cloraminas (WHO, 2006).

É importante a avaliação dos aspectos físico-químicos a fim de garantir uma funcionalidade do ambiente e a saúde dos seus frequentadores, já que essa manutenção tem como objetivo eliminar microrganismos causadores de doenças e manter a água em condições adequada para o banho.

As doenças poderão ser adquiridas, não somente com o contato com a água de uso da piscina propriamente dita, conforme cita Macedo (2003), mas também nas proximidades dela. As doenças que podem ser proliferadas são as de infecções da epiderme como furunculoses, eczemas, micoses, vulvovaginite gonogócica, lesões cutâneas, dermatomicose, candidíase cutânea, pitiriase versicolor, piodermites, resfriados, sinusites, inflamações da garganta, dos olhos, ouvidos, nariz, febre tifóide, paratifóide, disenterias, pólio e hepatite A.

Neste intuito este artigo se propõe a analisar a estrutura física e o $\mathrm{pH}$ das piscinas dos clubes aquáticos no sertão paraibano.

\section{MATERIAL E MÉTODOS}

Para avaliação foram coletadas, amostras de águas de diferentes piscinas públicas, sendo as mesmas identificadas por números cada piscina recebeu um número, a saber, amostra 1 , proveniente da piscina 1 , amostra 2, proveniente da piscina 2 , e, amostra 3 proveniente da piscina 3 . Todas as piscinas estavam equipadas com sistemas de recirculação e tratamento de água. As coletas foram realizadas de acordo com a programação de cada clube disponibilizada pelo responsável.

Para verificar a estrutura física e a presença de material flutuante utilizou-se uma máquina fotográfica para registro, e para análise de $\mathrm{pH}$ foi feita análise in loco com um pHmetro portátil da marca Hanna.

\section{RESULTADOS E DISCUSSÃO}

Foi possível observar a presença de materiais flutuantes estranhas na amostra 1 e 2 como ilustra a Figura 1 e a presença de lodo nas frestas dos azulejos conforme imagem da amostra 3. Cada amostra foi proveniente de uma piscina diferente, conforme é possível detectar todas as piscinas públicas analisadas apresentam material flutuante de natureza estranha. De acordo com a NBR 10818/1989, este tipo de material deve ser ausente, pois a presença de fungos e impurezas pode causar danos à saúde dos banhistas como as doenças de pele como micose, frieira, molusco contagioso, entre outras. Nos três casos foi possível verificar a falta de segurança na estrutura física das piscinas públicas do município como apresenta a Figura 2, nas respectivas amostras 1, 2, 3 a e $3 b$. 
Figura 1: Presença de matérias flutuantes estranhas nas amostras 1, 2 e 3.
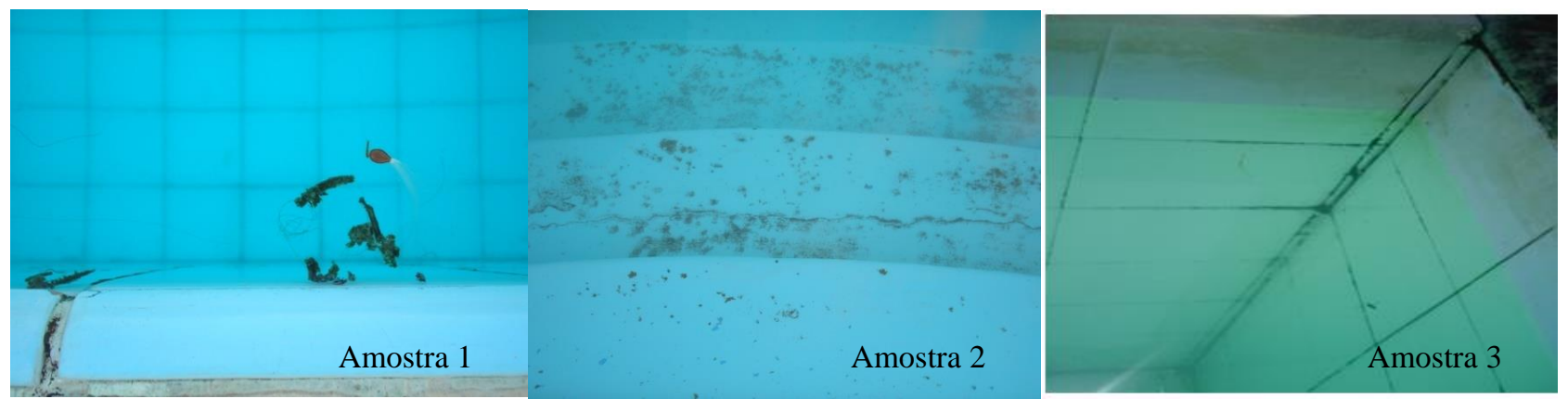

Fonte: Arquivo pessoal, 2015.

Figura 2: Falta de segurança na estrutura física conforme amostras 1, 2, 3a e 3b.

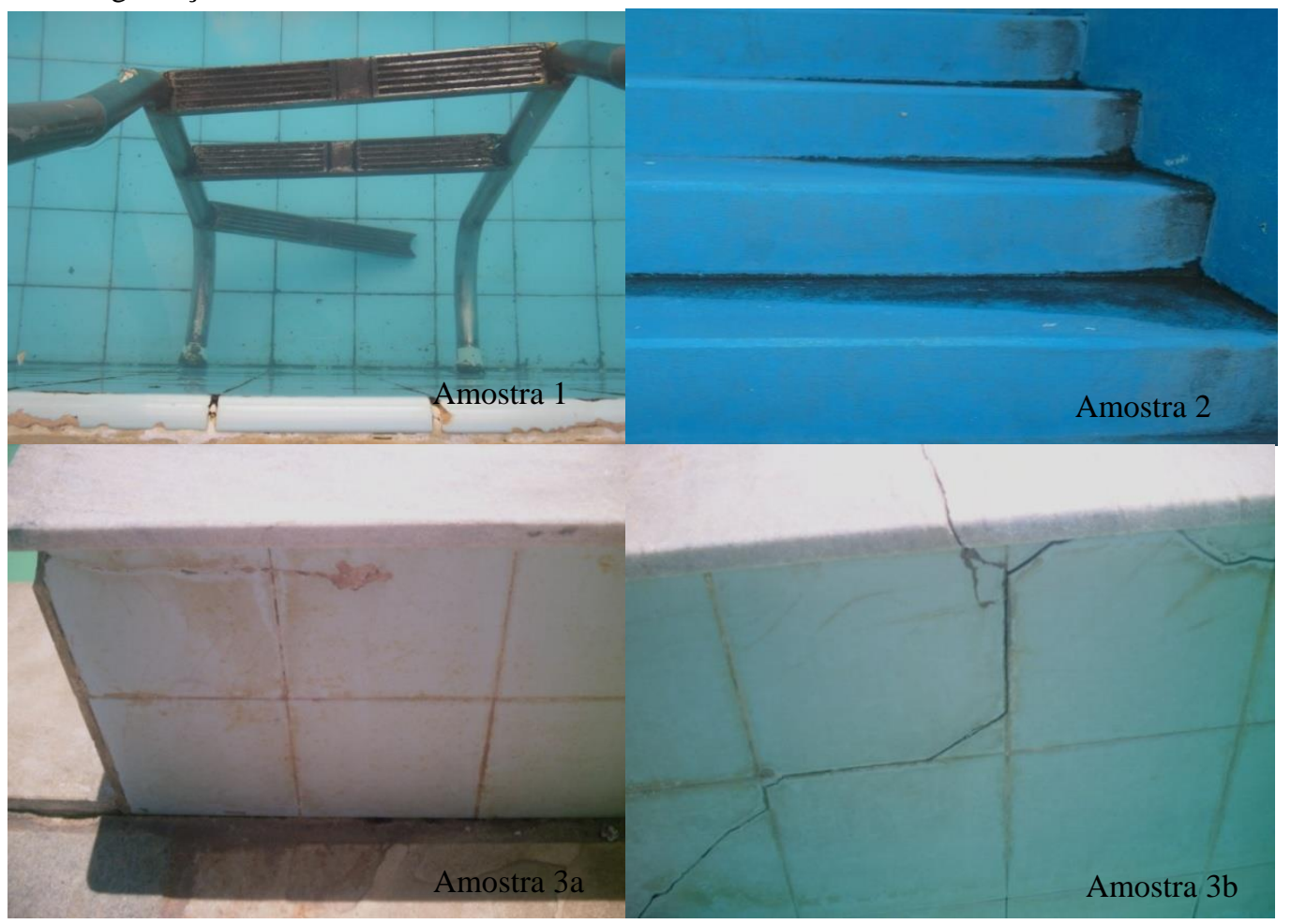

Fonte: Arquivo pessoal, 2015.

De acordo com os responsáveis as piscinas todas são tratadas com sulfato de alumínio, clarificante, cloro ou algicida, mostrando um padrão de limpeza segundo as normas da ABNT - NBR 11238/1990.

Para o pH como é possível observar na tabela 1 , a média dos valores de pH das amostras 1 e 3 estão em acordo com a NBR 10818/1989 que diz que os valores de $\mathrm{pH}$ deve ser entre 7,2 e 7,8. Já a amostra 2 a média do $\mathrm{pH}$ foi 7,0 apesar de estar bem próximo do $\mathrm{pH}$ ideal já começa a ser prejudicial aos olhos bem como a estrutura física da piscina podendo ocasionar corrosões. Segundo Oliveira (2003), o controle do $\mathrm{pH}$ é necessário uma vez que águas com $\mathrm{pH}$ muito baixo ou muito elevado podem ser lesivas para pele e mucosas de banhistas, causando alergias e irritações.

Tabela 1 - Média dos valores de $\mathrm{pH}$ da água das piscinas das amostras 1,2 e 3

\begin{tabular}{c|c}
\hline Amostra & $\mathrm{pH}$ \\
\hline 1 & 7,6 \\
2 & 7,0 \\
3 & 7,2 \\
\hline
\end{tabular}

Valores de pH entre 7,2 e 7,6 são ideais para eficácia dos produtos químicos utilizados para o tratamento da piscina, pois eles atuam com maior eficácia. Segundo Pedroso (2009), o valor do $\mathrm{pH}$ do liquido do globo ocular e 7,4, sendo este também o valor ideal para a água de uma piscina, por isso, o intervalo ótimo de $\mathrm{pH}$ corresponde a valores entre 7,4 e 7,6. Outro problema relacionado ao $\mathrm{pH}$ é a turbidez que ocorre com a elevação do $\mathrm{pH}$

As piscinas 1 e 3 atenderam a NBR 10818/1989 sendo assim não oferecem riscos de provocar irritação nos olhos, pele e mucosas dos banhistas. É possível verificar também que com estes valores de $\mathrm{pH}$ a água não provocará danos a parte metálica da piscina por não haver risco de corrosão da água. Já a piscina 2 o pH médio das análises mostrou-se fora do padrão, já podendo provocar irritação nos olhos e algum problema de corrosão na parte metálica das piscinas sendo necessário uma correção que segundo (PEDROSO, 2009), quando o valor do pH se encontrar fora do intervalo estipulado, é necessário efetuar a correção com ácido clorídrico (acidificante) caso o valor de $\mathrm{pH}$ seja superior ao máximo valor estipulado, ou com soda cáustica 
(alcalinizante) se o valor de $\mathrm{pH}$ for inferior ao mínimo estipulado.

\section{CONCLUSÃO}

É importante ressaltar dois aspectos sobre o uso de piscinas, a importância social e a importância sanitária. Sobre a importância social é indiscutível que um clube aquático proporciona encontros sociais e práticas de esportes aquáticos coletivos o que levam a uma melhor qualidade de vida. Já a importância sanitária é um ponto extremamente discutível, pois se não tiver dentro das condições exigidas pela norma vigente, pode oferecer sérios riscos a saúde do banhista.

As piscinas analisadas apresentaram problemas de estrutura preocupante, pois idosos e crianças frequentam o local, podendo se machucar ao tentar subir em escadas quebradas e se cortarem em pontas de azulejos quebradas.

Apesar de NBRs estarem em vigência há falta de fiscalização, atrelado ao fato do Estado da Paraíba e o município de Pombal não possuírem normatização ou regulamentação própria que obrigue os mesmos a se adequarem para propiciar aos usuários uma qualidade estrutural mínima dificulta a fiscalização e a cobrança por parte das autoridades e da população.

Quanto ao $\mathrm{pH}$ foi possível notar que duas das piscinas estão dentro dos padrões estabelecidos pela NBR 10818/1989 sendo que a outra precisa se adequar para oferecer maior segurança e conforto aos banhistas.

Conclui-se então, que para proporcionar diversão e ao mesmo tempo isentar possibilidades de contaminação aos usuários, os dirigentes e funcionários responsáveis pelos clubes, deveriam conscientizar-se da importância em construir e operar as piscinas de acordo com as normas estabelecidas e com tratamento químico eficiente, respeitando as faixas ideais para a conservação da água, proporcionando assim, melhor qualidade de vida aos usuários.

\section{REFERÊNCIAS BIBLIOGRÁFICAS}

ASSOCIAÇÃO BRASILEIRA DE NORMAS TÉCNICAS (ABNT). NBR-10818: Qualidade de águas de piscinas. Nov. 1989, p. 2.

ASSOCIAÇÃO BRASILEIRA DE NORMAS TÉCNICAS (ABNT). NBR-11238: Segurança e higiene de piscinas - Procedimento. Ago. 1990.

BELEZA, V. M. SANTOS, R. PINTO, M. Piscinas Tratamento de águas e utilização de energia. Politema - Fundação Instituto Politécnico do Porto, Porto, 2007.

OLIVEIRA, MARIÁ VENDRAMINI CASTRIGNANO. Princípios Básicos do Saneamento do Meio. São Paulo, 2003.

PEDROSO, M. J. S. L. C. Exposição ocupacional em piscinas cobertas do tipo I e II. Tese de Mestrado em Saúde Pública - Universidade do Porto, Porto, (2009). 